\title{
Marburg Multiple Sclerosis Variant: Complete Remission with Very Early Administration of Mitoxantrone-A Case Report
}

\author{
Nicolas Capet (D) · Michael Levraut · Adrien Delourme • \\ Oceane Thomel-Rocchi • Véronique Bourg • Philippe Cabre • \\ Fanny Vandenbos · Lydiane Mondot · Christine Lebrun-Frenay
}

Received: September 30, 2021 / Accepted: November 23, 2021 / Published online: December 2, 2021

(C) The Author(s) 2021

\section{ABSTRACT}

Marburg variant is a severe and fulminant pseudotumor form of multiple sclerosis (MS) with high morbidity and mortality rates.

N. Capet $(\varangle) \cdot$ M. Levraut · C. Lebrun-Frenay URRIS, Unité de Recherche Clinique Cote d'AzurUR2CA-CRCSEP- Hôpital Pasteur 2, 30 voie romaine, 06000 Nice, France

e-mail: n.capet@gmail.com

\section{N. Capet}

Department of Internal Medicine, Princess Grace Hospital Center, Pasteur, Monaco

N. Capet · A. Delourme · O. Thomel-Rocchi .

V. Bourg · C. Lebrun-Frenay

Service de Neurologie- Hôpital Pasteur 2, Centre Hospitalier Universitaire de Nice, 30 voie Romaine, 06000 Nice, France

\section{Levraut}

Service de médecine interne- Hôpital l'Archet 1, Centre Hospitalier Universitaire de Nice, 151 route Saint Antoine de Ginestière, 06200 Nice, France

P. Cabre

Service de Neurologie, Université Antilles-Guyane, Hôpital Pierre Zobda Quitmann, Fort de France, Antilles Françaises, Martinique

F. Vandenbos

Central Laboratory of Pathology, Pasteur I

University Hospital, UCA, Nice, France

\section{Mondot}

Service de Radiologie, Hôpital Pasteur 2, Centre Hospitalier Universitaire de Nice, 30 voie Romaine, 06000 Nice, France
Because of its scarcity, it remains incompletely characterized and physicians' experiences will influence the treatment. We report the inflammatory explosive case of a 31-year-old woman presenting with rapid neurological degradation of histology proven Marburg's disease, successfully treated with early administration of Mitoxantrone (MITX). To our knowledge, it is the first case describing complete remission after MITX in a biopsy-proven condition.

Keywords: Marburg's variant; Multiple sclerosis; Mitoxantrone; Case report 


\section{Key Summary Points}

Marburg variant is a very rare, severe, and fulminant pseudotumor form of multiple sclerosis (MS) with high morbidity and mortality rates.

Usual immunosuppressive treatments for aggressive demyelinating disease, such as high doses of corticosteroids and plasmapheresis, do not provide satisfactory clinical improvement in Marburg variant of MS.

We report the complete clinical remission with early administration of Mitoxantrone in a 31-year-old women after neuropathological confirmation of Marburg type.

Early cerebral biopsy to rule out differential diagnoses of aggressive MS and prompt administration of Mitoxantrone could be an effective diagnostic and therapeutic attitude for the management of Marburg variant of MS.

\section{INTRODUCTION}

Marburg's variant of multiple sclerosis (MS), first described by the Austrian neurologist Otto Marburg in 1905, is a very rare demyelinating disease that usually leads to severe disability or death within weeks to months [1]. Only few cases considered the use of intense immunosuppression but none of them reported the benefit of Mitoxantrone (MITX) with diagnosis histological confirmation. Indeed, we report the unique case of a young patient very early treated with MITX right after the cerebral biopsy performed because of the vital prognosis involved. Clinical features, MRI, and neuropathology characteristics are discussed considering demyelinating pathophysiology and immunosuppression challenge of a promising Marburg's variant effective treatment. Although no clinical studies have been carried out because of the scarcity of this very fulminant disease, we report the complete remission using MITX while the usual therapies reported have most often failed.

\section{CASE REPORT}

A 31-year-old immunocompetent right-handed Russian woman with no medical history of family history of MS presented to the emergency department for sudden dysarthria and left central facial palsy. She did not report fever or any symptoms evocative of an active infection, but she reported a mild SARS-CoV2 infection 4 months previously; she was not taking any medication or toxic. During the first $24 \mathrm{~h}$, she experienced very fast worsening of neurological symptoms. The first clinical examinations revealed left proportional hemiplegia with left Babinski sign and complete left anesthesia, anosognosia with left-sided visuospatial hemineglect, and fluctuating altered consciousness. Magnetic resonance imaging showed a large right frontal pseudo-nodular lesion, hyperintense on diffusion and T2-FLAIR sequences, gadolinium-enhanced, without surrounding edema (Fig. 1a). Extensive blood analysis did not support systemic inflammation (normal white blood cell count, C-reactive protein, gammaglobulins, and sedimentation rate). Infectious and immune blood tests including HIV, viral hepatitis, syphilis, Lyme, herpes complex viruses, quantiFERON-TB Gold in-tube assay, anti-nuclear antibodies (Ab), antineutrophil cytoplasmic antibodies, cryoglobulins as well as anti-aquaporin-4 (AQP4) and myelin oligodendrocyte glycoprotein (MOG) Ab were all negative. To evaluate the AQP4 IgG and MOG-ab testing, samples were tested by flow cytometry based on the use of a stable human embryonic kidney cell line overexpressing the M23 isoform of aquaporin-4 performed by a cell-based assay. Cerebrospinal fluid (CSF) analysis exhibited a normal white blood cell count $\left(4 / \mathrm{mm}^{3}\right), 45 \mathrm{mg} / \mathrm{dL}$ protein, and $65 \mathrm{mg} /$ $\mathrm{dL}$ glucose (serum $94 \mathrm{mg} / \mathrm{dl}$ ) without oligoclonal bands. Kappa-free light chain index was slightly elevated (6.6) and CSF cytokine profile 

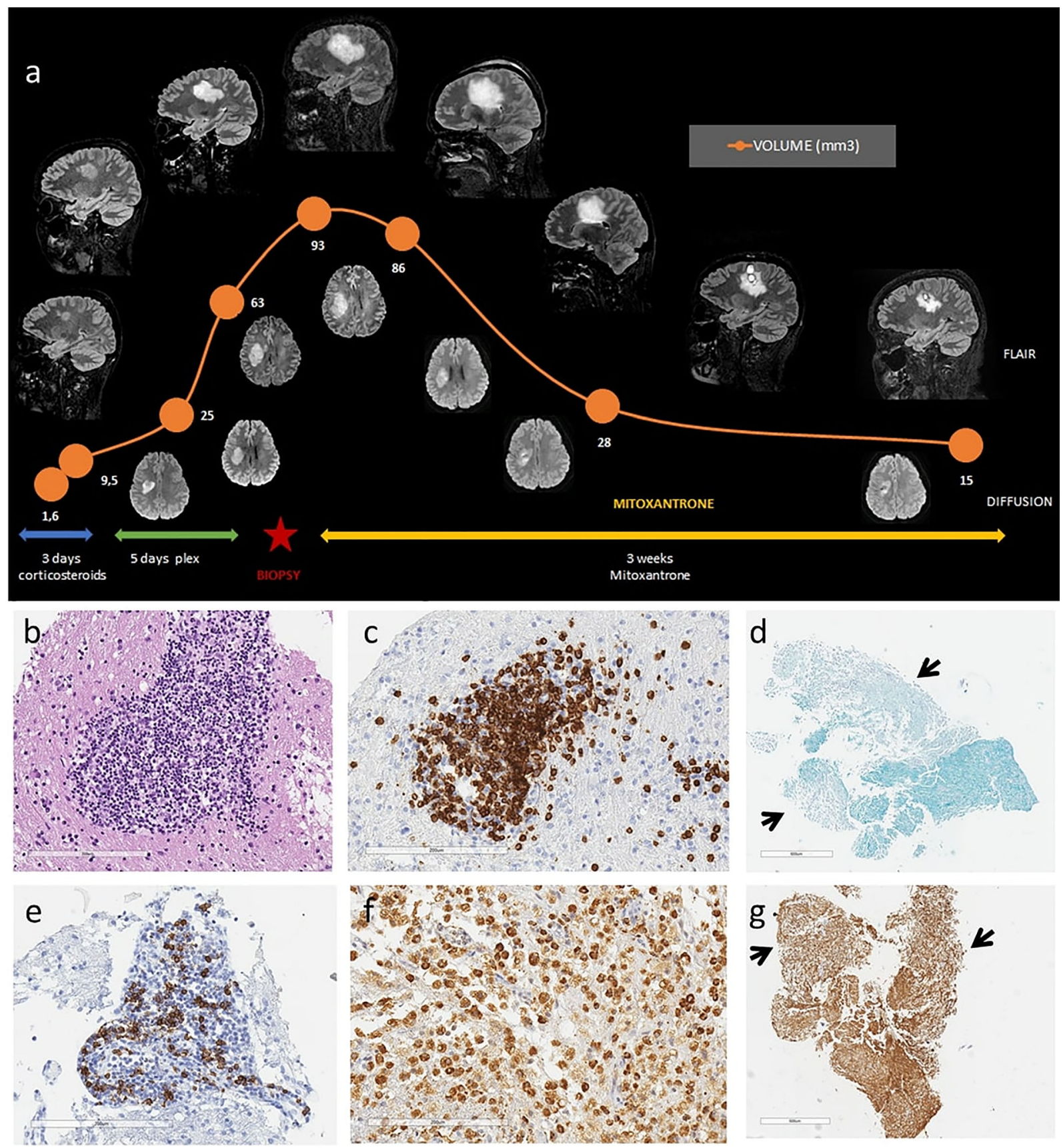

Fig. 1 Magnetic resonance imaging and biopsy neuropathological findings. a MRI follow-up in sagittal fluidattenuated inversion recovery (FLAIR) and axial diffusion images tracked over time revel a large hyperintense right frontal lesion with imprecise boundaries extended to the white matter. b Lymphoid nodule in brain section (hematoxylin-eosin-saffron HES $\times 200$ ). c Lymphoid nodules are mostly composed of $\mathrm{T}$ lymphocytes (antiCD3 immunostaining $\times 200$ ). d Luxol Fast Blue staining $\times 40$ reveals myelin loss in some areas (arrow). e AntiCD20 immunostaining $\times 200$ revealed some $B$ lymphocytes in lymphoid nodules. f Anti-CD68 immunostaining $\times 200$ showed numerous positive macrophages. g Anti-neurofilament immunostaining $(\times 40)$ showed that axons are preserved in demyelinated areas (arrow) 
showed an elevated concentration of IL-10 $(3.39 \mathrm{pg} / \mathrm{mL})$ and soluble IL2-receptor $(156 \mathrm{pg} /$ $\mathrm{mL}$ ) whereas other biomarkers did not support infection (IL- $1 \beta<0.32 \mathrm{pg} / \mathrm{mL}, \quad$ IL- $6=4.04 \mathrm{pg}$ / $\mathrm{mL}, \quad$ INF- $\alpha<2.92 \mathrm{pg} / \mathrm{mL}$ ). Attempts to detect CSF infectious agents, including Gram staining, culture, and PCR for neurotrophic viruses (including SARS-CoV2), were also negative. During the diagnostic work-up, she received intravenous (IV) methylprednisolone $1 \mathrm{~g} /$ day for three consecutive days ( $3 \mathrm{~g}$ in total) associated with five sessions of plasma exchange without any clinical modification. Repeated brain MRI showed significant growth of the frontal lesion day by day (from $1.6 \mathrm{~cm}^{3}$ at day 1 to $9.6 \mathrm{~cm}^{3}$ on day 14) with maintained gadolinium enhancement, the appearance of surrounded edema and two other inflammatory deep white matter hyperintensities (Fig. 1a). Despite the combined IV corticotherapy and plasmapheresis, in the absence of clinical improvement and to exclude differential diagnosis, a brain biopsy of the right frontal lesion was performed at day 14. At this stage, it was decided to perform a brain biopsy collegially for two main reasons. First, the patient showed no sign of clinical improvement and kept getting worse despite of the administration of high doses of corticosteroids and successively plasmapheresis. And second, and before deciding to introduce Mitoxantrone in a young woman of childbearing age, the multidisciplinary consultation meeting suggested excluding differential diagnosis such as intravascular lymphoma in the absence of CSF anomalies. The pathological analysis of the brain tissue revealed an active demyelinating process (Fig. 1d) without any axonal loss (Fig. 1g), but with an important infiltrate of polyclonal lymphocytes (mostly $\mathrm{T}$ cells) (Fig. 1b, c, e) and macrophages (Fig. 1f). No tumoral cells were found. Because of the aggressiveness of demyelinating disease, it was decided in a multidisciplinary board to start at day 21 after the diagnosis with IV Mitoxantrone, $12 \mathrm{mg} / \mathrm{m}^{2}$, associated with a novel IV pulse steroid therapy for 5 days, relayed to $1 \mathrm{mg} / \mathrm{kg} /$ day oral prednisone. At the beginning of MITX, her Expanded Disability Status Scale (EDSS) was 8 with altered consciousness. Three weeks after the first MITX infusion, most of her neurological deficits improved except for a slight left brachio-facial sensory deficit (EDSS 2), and brain MRI showed a five-times decrease of the frontal lesion $\left(9.6 \mathrm{~cm}^{3}\right.$ before MITX to 1.5 $\mathrm{cm}^{3}$ ). She was discharged from the hospital, and steroids were progressively tapered. Two other MITX infusions $(20 \mathrm{mg} /$ dose $)$ were administered monthly without any clinical or hematological side effects. At 6 months, complete remission was noted (EDSS:1) without cognitive impairment, and she was able to start an antiCD20 maintenance treatment. Written informed consent to publish was obtained from the patient included in this study to report the first case describing complete remission after MITX in a biopsy-proven condition.

\section{DISCUSSION}

Since Otto Marburg's first description of the MS variant thatgaveititsnamein 1905 , thedifferential diagnosis of fulminant demyelinating diseases remains challenging [1]. In our case, Marburg's diagnosis was supported by a typical clinical, radiological, and pathological analysis. Although the details of the pathogenic heterogeneity of the Marburg type and prototypical MS have not been clarified, authors have discussed the occurrence of inhibition of neurogenesis blocked in Marburg type unlike the remyelination observed in the typical course of MS [2]. Other studies have suggested centralnervoussystem $(\mathrm{CNS})$ vasculitisand that pathogenic peripheral lymphocytes could infiltrate the CNSvia meningealand parenchymal vessels that cause perivascular demyelinating lesions, leading to massive and continuous inflammatory into the CNS with B-T-cell interactions appearing to play a role in early progression and severity of the disease $[3,4]$. Such a complex pathophysiology could explain the effectiveness of MITX in aggressive forms of MS in reducing disease progression through a variety of different mechanisms of action, suppressing the proliferation of T cells, B cells, and macrophages, impairing antigen presentation and the secretion of proinflammatory cytokines, enhancing T-cell suppressor function, inhibiting B-cell function and antibody production, and, finally, macrophagemediated myelin degradation [5]. Even if our 
patient suffered mild COVID-19 infection a few months before, acute demyelinating encephalomyelitisdiagnosiswasnotsupportedby the absence of spine or gray matter involvement, the appearance ofnewinflammatory white matter hyperintensities under steroid and plasma exchange therapies, the brain pathology, and the long time to infection [6]. The brain biopsy excluded other diagnoses. such as a brain tumor, lymphoma, infection, or cerebral vasculitis. Most of our knowledge about Marburg's MS variant's pathological findings comes from post-mortem analysis $[7,8]$. Thetypical histological resultshows a significant myelin loss with severe axonal injury with or without necrosis, associated with macrophageandlymphocytecellularinfiltrate[4].Inthis case, we found that, even being an aggressive form of MS, oligoclonal bands and kappa-free light chainindexwere notinformativeenoughtoassess the diagnosis. Moreover, CSF cytokines showed elevated IL-10 and s-IL2R without elevation of IL-6 that could supportlymphoma diagnosis. Added to the normal lymphocyte infiltrate, mainly compounded ofT-lymphocytes, it can suggest a crucial role of the Th1/Treg balance in Marburg's disease describedinMSforms [9]. Becauseofitsscarcity, no randomized controlled trial is available to support treatment evidence in such fulminant cases. Most reported patients were treated using IV steroids or plasma exchange therapy without long-term efficacy [7-12]. Recent evidence does not support fingolimod and natalizumab to treat tumefactive MS, including Marburg's variant [13]. Only a few cases have shown long-term response to immunosuppressants, and some authors have reported the efficacy of high-dose cyclophosphamide and alemtuzumab [14-17]. Unfortunately, the European Medicine Agency has restricted alemtuzumab use since 2019 because of severe advisory side effects such as fulminant hepatitis, severe cardiovascular diseases, and hemophagocytic lymphohistiocytosis. Since 1997, therapeutic effect of Mitoxantrone in very aggressive MS has been well documented [18]. To the best of our knowledge, only three cases have described the efficacy of MITX in Marburg's condition[19-21]. However, in thesereports, therewas no neuropathological evidence and the diagnosis could have been challenged because of its atypical radiological description [18]. As described previously in a case report of Marburg variant, the patient had no response to treatment with methylprednisolone but improved and recovered after treatment with MITX with potent anti-inflammatory effects and demonstrated efficacy in worsening MS, suggesting that it may be an appropriate agent for the treatment of Marburg variant MS despite the absence the diagnosis confirmation with the neuropathological result of a cerebral biopsy [22]. In our report, MITX has been used to allow rapid and necessary immunosuppression but cannot be used as a long-term treatment because of its potentially severe cardiovascular side effects. Moreover, since these reports, the availability of rituximab or anti-CD20 blocker seems to be the most effective therapeutic relay after administration of MTX as described in our study, and highlights the need to have case series reporting long-term survival to know which agentshould begiven to maintain remission in the Marburg variant of MS.

\section{CONCLUSION}

Our case illustrates that MITX can be one of the most effective treatment to assess early remission in the acute phase of aggressive Marburg's MS variant despite high dose of corticosteroids and plasmapheresis. Our report is the first to confirm the benefit of MITX supported by cerebral neuropathological proof of MS Marburg's variant.

\section{ACKNOWLEDGEMENTS}

We thank the participant of the study.

Funding. No funding or sponsorship was received for this study or publication of this article.

Authorship. All named authors meet the International Committee of Medical Journal Editors (ICMJE) criteria for authorship for this article, take responsibility for the integrity of the work as a whole, and have given their approval for this version to be published. 
Authors' Contributions. Nicolas Capet, Michael Levraut and Christine Lebrun-Frenay wrote the initial draft and revised it. Adrien Delourme, Veronique Bourg, Oceane ThomelRocchi and Philippe Cabre participated in the medical management and therapeuthic decisions. Fanny Vandenbos were the anatomopathologist in charge and Lydiane Mondot provided the MRI data as neuroradiologist.

Disclosures. Nicolas Capet, Michael Levraut, Adrien Delourme, Oceane Thomel-Rocchi, Véronique Bourg, Philippe Cabre, Fanny Vandenbos, Lydiane Mondot and Christine LebrunFrenay declare no conflict of interest.

Compliance with Ethics Guidelines. No identifiable information was disclosed in writing this case report; however, written consent was obtained from the patient for publishing the medical data for scientific purposes.

Data Availability. Data sharing is not applicable to this article as no datasets were generated or analyzed during the current study.

Open Access. This article is licensed under a Creative Commons Attribution-NonCommercial 4.0 International License, which permits any non-commercial use, sharing, adaptation, distribution and reproduction in any medium or format, as long as you give appropriate credit to the original author(s) and the source, provide a link to the Creative Commons licence, and indicate if changes were made. The images or other third party material in this article are included in the article's Creative Commons licence, unless indicated otherwise in a credit line to the material. If material is not included in the article's Creative Commons licence and your intended use is not permitted by statutory regulation or exceeds the permitted use, you will need to obtain permission directly from the copyright holder. To view a copy of this licence, visit http:// creativecommons.org/licenses/by-nc/4.0/.

\section{REFERENCES}

1. Marburg O. Die sogennante akute multiple Sklerose. Mitt Ges Inn Med Kinderheilk Wien. 1905;4: 200.

2. Beniac DR, Wood DD, Palaniyar N, Ottensmeyer FP, Moscarello MA, Harauz G. Marburg's variant of multiple sclerosis correlates with a less compact structure of myelin basic protein. Mol Cell Biol Res Commun. 1999;1(1):48-51. https://doi.org/10. 1006/mcbr.1999.0111 (PMID: 10329477).

3. Elenein RG, Sharer LR, Cook SD, Pachner AR, Michaels J, Hillen ME. A second case of Marburg's variant of multiple sclerosis with vasculitis and extensive demyelination. Mult Scler. 2011;17(12): 1531-8. 1352458511414042 (PMID: 21816761).

4. Suzuki M, Kawasaki H, Masaki K, Suzuki SO, Terada T, Tsuchida T, et al. An autopsy case of the marburg variant of multiple sclerosis (acute multiple sclerosis). Intern Med. 2013;52(16):2532.

5. Fox EJ. Mechanism of action of mitoxantrone. Neurology. 2004;63(12 Suppl 6):S15-8. https:/doi. org/10.1212/wnl.63.12_suppl_6.s15 15623664).

6. Parsons T, Banks S, Bae C, Gelber J, Alahmadi H, Tichauer M. COVID-19-associated acute disseminated encephalomyelitis (ADEM). J Neurol. 2020;267(10):2799802.

7. Algahtani H, Shirah B, Alassiri A. Tumefactive demyelinating lesions: a comprehensive review. Mult Scler Relat Disord. 2017;14:729.

8. Nunes J, Radbruch H, Walz R, Lin K, Stenzel W, Prokop S, et al. The most fulminant course of the Marburg variant of multiple sclerosis-autopsy findings. Mult Scler J. 2015;21(4):4857.

9. Duan H, Luo Y, Hao H, Feng L, Zhang Y, Lu D, et al. Soluble CD146 in cerebrospinal fluid of active multiple sclerosis. Neuroscience. 2013;235:1626.

10. Vakrakou AG, Tzanetakos D, Argyrakos T, Koutsis G, Evangelopoulos M-E, Andreadou E, et al. Recurrent fulminant tumefactive demyelination with Marburg-like features and atypical presentation: therapeutic dilemmas and review of literature. Front Neurol. 2020;11:536. 
11. Ayrignac $X$, Carra-Dallière $C$, Labauge $P$. Atypical inflammatory demyelinating lesions and atypical multiple sclerosis. Rev Neurol (Paris). 2018;174(6): 40818.

12. Simon JH, Kleinschmidt-DeMasters BK. Variants of multiple sclerosis. Neuroimaging Clin N Am. 2008;18(4):70316.

13. Frederick MC, Cameron MH. Tumefactive demyelinating lesions in multiple sclerosis and associated disorders. Curr Neurol Neurosci Rep. 2016;16(3):26.

14. Nozaki K, Abou-Fayssal N. High dose cyclophosphamide treatment in Marburg variant multiple sclerosis. J Neurol Sci. 2010;296(12):1213.

15. Turatti M, Gajofatto A, Rossi F, Vedovello M, Benedetti MD. Long survival and clinical stability in Marburg's variant multiple sclerosis. Neurol Sci. 2010;31(6):80711.

16. Avila-Ornelas J, Labat E, Alfonso G, Serrano C, Fiorito F. An extremely aggressive case of Marburg's disease treated with high dose cyclophosphamide. A case report. Mult Scler Relat Disord. 2019;31:513.

17. Gobbin F, Marangi A, Orlandi R, Richelli S, Turatti $\mathrm{M}$, Calabrese $\mathrm{M}$, et al. A case of acute fulminant multiple sclerosis treated with alemtuzumab. Mult Scler Relat Disord. 2017;17:911.

18. Edan G, Miller D, Clanet M, Confavreux C, LyonCaen O, Lubetzki C, Brochet B, Berry I, Rolland Y, Froment JC, Cabanis E, Iba-Zizen MT, Gandon JM, Lai HM, Moseley I, Sabouraud O. Therapeutic effect of mitoxantrone combined with methylprednisolone in multiple sclerosis: a randomised multicentre study of active disease using MRI and clinical criteria. J Neurol Neurosurg Psychiatry. 1997;62(2):112-8. https://doi.org/10.1136/jnnp.62. 2.112.PMID:9048709;PMCID:PMC486720.

19. Susac JO, Murtagh FR, Egan RA, Berger JR, Bakshi R, Lincoff N, et al. MRI findings in Susac's syndrome. Neurology. 2003;61(12):17837.

20. Talab R, Kundrata Z. Marburg variant multiple sclerosis: a case report. Neuro Endocrinol Lett. 2011;32(4):415-20 (PMID: 21876497).

21. Manuel A, Vasudevan MC. A case of Marburg's variant of multiple sclerosis successfully treated with IVIg and mitoxantrone. Ann Indian Acad Neurol. 2021;24(1):92-4. https://doi.org/10.4103/ aian.AIAN_117_20.

22. Jeffery DR, Lefkowitz DS, Crittenden JP. Treatment of Marburg variant multiple sclerosis with mitoxantrone. J Neuroimaging. 2004;14(1):5862. 